\title{
Physical limnology of Italian lakes. 1. Relationship between morphometry and heat content
}

\author{
Walter AMBROSETTI* and Luigi BARBANTI \\ CNR Institute for Ecosystem Study, L.go Tonolli 50, 28922 Verbania-Pallanza, Italy \\ *e-mail corresponding author: w.ambrosetti@iii.to.cnr.it
}

\begin{abstract}
The influence of morphometry on maximum and minimum heat content and on pluriannual heat budgets of 31 Italian lakes is analysed. The energy parameters are highly correlated with the morphometric parameters through power regressions. The lakes which markedly deviate from the regression curves are examined on the basis of their environmental conditions or their internal hydrodynamics. In deep lakes (i.e. depth $>50 \mathrm{~m}$ ) there is a high correlation between depth and maximum and minimum heat content, while the heat budget is correlated only with fetch and depths of 50 and $90 \%$ annual heat exchange. In shallow lakes there is no relationship between fetch and heat budget, while it is high with all the considered depths. This is due to the different thickness of the water layer, in relation to the maximum depth, which is involved in the annual heat exchanges. We evaluated the water thicknesses within which 40 to $90 \%$ of the total heat exchanges take place; the results showed that in deep lakes $90 \%$ of the energy exchange is confined to a layer comprising 14-16\% of the maximum depth, while in shallow lakes it can reach $82 \%$ of the maximum depth. In Lago Maggiore the 90\% heat exchange depth increased by $0.34 \mathrm{~m}$ per year from 1963 to 1999, thus contributing to heating the whole water mass of the lake.
\end{abstract}

Key words: heat content, heat budget, heat exchange, morphometry

\section{INTRODUCTION}

Numerous studies performed at different latitudes Hutchinson (1957), Gorham (1964), Reed(1970), Schindler (1971), Timms(1975), Viner (1984) Wetzel (1983), Allot (1986), Kling (1988), Henry \& Barbosa (1989), Bowling (1990), Geller (1992), Kjensmo (1994) have demonstrated that the maximum and minimum heat contents in lakes throughout the world, and consequently their heat budgets, are linked to volume, mean or maximum depth, or to the surface area of the lake.

Winter and summer heat content, deep water warming, and the heat budget in each lake are influenced by various factors, including latitude, altitude, exposure to wind, inflow from tributaries and morphometrical parameters. The last of these factors is particularly important, because the shape of a lake has a major influence on the efficiency of the heat distribution to the deep layers by the wind, and consequently the quantity of internal energy which can be stored or lost.

In fact, the formation and thickness of the epilimnion, the seasonal stratification trend and the winter vertical mixing in lakes are dependent on internal hydrodynamic mechanisms which in turn are influenced by the size of the lakes. Thus the thermal properties of lakes, usually described in terms of stratification and circulation cycles with a comparison between the thermal profiles measured at different times of year, can be better understood through the use of energy parameters such as total and partial heat content within the water mass. These parameters may also be used to compare and analyse the behaviour of lakes with wide differences in size and geographic location.

One of our aims was to examine in detail the mean energy variations in the water mass in 31 Italian lakes in relation to their morphometric and geographic characteristics, making a distinction between deep and shallow lakes, to verify whether they store a quantity of thermal energy representative of their geographical location and the hydro-meteorological characteristics of the area in which they are located.

Another aim was to identify and quantify the thicknesses of the water layers involved in heat exchange over the year, and to verify how these interact with lake hydrodynamics.

To verify the thermal behaviour of 31 selected Italian lakes, we looked at the following physical characteristics: volume $(\mathrm{V})$, maximum depth $\left(\mathrm{z}_{\mathrm{max}}\right)$, mean depth $\left(\mathrm{z}_{\text {mean }}\right)$, fetch area $\left(\mathrm{F}_{\text {area }}=\right.$ Area $\left.^{1 / 2}\right)$, effective fetch $\left(\mathrm{F}_{\text {eff }}=\right.$ (maximum effective length + maximum effective width)/2), area (A), depth of epilimnion $\left(\mathrm{z}_{\mathrm{epi}}\right)$, depth of thermocline $\left(\mathrm{z}_{\text {term }}\right)$, maximum heat content $\left(\mathrm{Q}_{\mathrm{tmax}}\right)$, minimum heat content $\left(\mathrm{Q}_{\mathrm{tmin}}\right)$, heat budget $\left(\mathrm{B}_{\mathrm{t}}\right)$ and depths of 50 and $90 \%$ annual heat exchange in the lakes, indicated by $\mathrm{z}_{50}$ and $\mathrm{z}_{90}$, respectively.

\section{METHODS}

Most of the lakes studied are located in the Sudalpine area between $45^{\circ} 19^{\prime} 25^{\prime \prime}$ and $46^{\circ} 04^{\prime} 54^{\prime \prime}$ of latitude North, and only four are situated in the Central Italian lake district between $41^{\circ} 42^{\prime} 45^{\prime \prime}$ and $42^{\circ} 35^{\prime}$ (Fig. 1). 

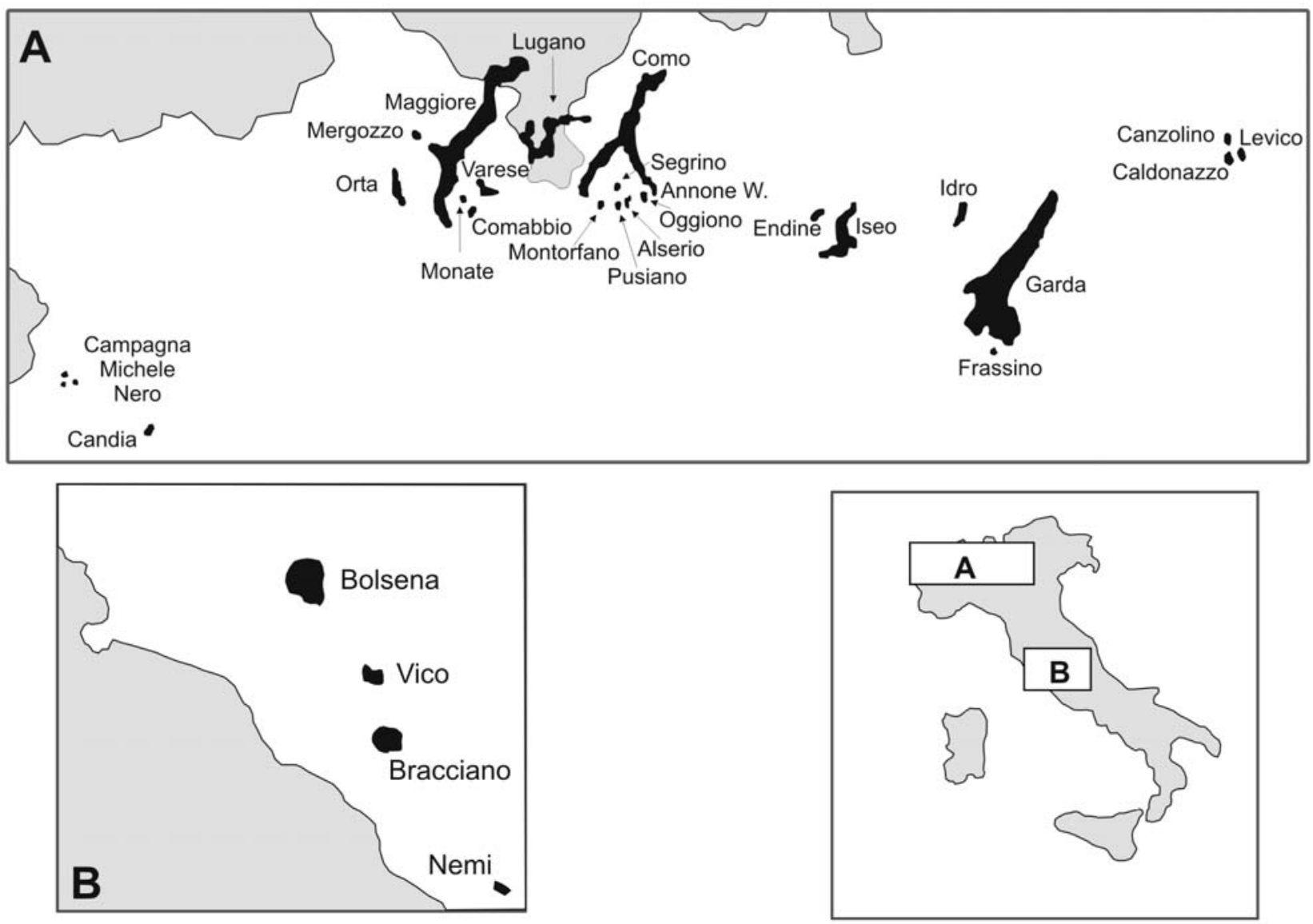

Fig. 1. Geographic location of surveyed lakes.

They lie at altitudes between 65 (Garda) and 540 (Canzolino) $\mathrm{m}$ a.s.l. The lakes in the northern area belong, according to the regional classification of Italy suggested by Mennella $(1967 ; 1970)$, to the so-called "sub regione dei laghi", a sub-type distinguished from the climate of the Po Plain by the very presence of the lakes (especially the largest of them). This climate is characterised by a restricted annual range of air temperature, and by high rainfall (Mennella 1970). The Central Italian lakes belong to the "Medio Tirreno" climatic compartment, and occupy the highest part of the volcanic area which makes up the "Anti-Appennino Laziale"; due to their sub-littoral geographical location, they have a maritime climate with generally mild winters and hot summers.

Because of their distinct morphometric characteristics the three main basins of Lake Lugano are considered separately: the basins of Ponte Tresa (Lugano PT), Porlezza (Lugano NB) and Figino (Lugano FG), separated by the Lavena narrows and the Melide dam. The two basins of Lake Annone (West Annone and Oggiono) are also considered separately.

We used pluriannual water temperature data to calculate the vertical distribution of the caloric content in 31 selected Italian lakes with depths varying between 5 and $410 \mathrm{~m}$; the calculation was based on the LIMNOX Program (1997) which was supplied by Bob Banens (University of New England, Armidale, NSW, Australia). Using this programme we calculated the total quantity of heat content, as well as its metre by metre distribution from surface to bottom.

Table 1 shows, in addition to the morphometric parameters listed above, the mean annual heat budget and the maximum, minimum and mean quantities of heat contained in the water mass of the 31 selected lakes. These values are strictly dependent on the moment of the annual cycle at which the heat measurements were taken. Since there is no way of knowing in advance when the moments of maximum and minimum heat content will occur (Stewart 1973), the real values lead to an underestimate of the quantities of heat present, obviously with a lesser degree of uncertainty as regards the winter quantities, in that fluctuations in temperature are lower in winter (Ferris \& Burton 1988). In summer any errors may be considerable if the sampling frequency is longer than a month (Bowling 1990). In this study, 60\% of the measurements were taken weekly or fortnightly, and in the other $40 \%$ of cases sampling frequency was never longer than one month. It should also be noted that lakes belonging to the climates analysed here have 
Tab. 1. Morphometric and heat parameters of 31 Italian lakes.

\begin{tabular}{|c|c|c|c|c|c|c|c|c|c|c|c|}
\hline & & $\begin{array}{l}\text { Mean alt. } \\
\text { m (a.s.l.) }\end{array}$ & $\begin{array}{c}\mathrm{A} \\
\left(\mathrm{km}^{2}\right)\end{array}$ & $\begin{array}{c}\mathrm{V} \\
\left(\mathrm{km}^{3}\right)\end{array}$ & $\begin{array}{l}Z_{\max } \\
(\mathrm{m})\end{array}$ & $\begin{array}{c}Z_{\text {mean }} \\
(\mathrm{m})\end{array}$ & $\begin{array}{c}\mathrm{F}_{\text {eff }} \\
(\mathrm{km})\end{array}$ & $\begin{array}{l}\mathrm{F}_{\text {area }} \\
(\mathrm{km})\end{array}$ & $\begin{array}{c}\mathrm{Q}_{\mathrm{t} \min } \\
\left(\mathrm{MJ} \mathrm{m}^{-2}\right)\end{array}$ & $\begin{array}{c}\mathrm{Q}_{\mathrm{t} \max } \\
\left(\mathrm{MJ} \mathrm{m}^{-2}\right)\end{array}$ & $\begin{array}{c}\mathrm{B}_{\mathrm{t}} \\
\left(\mathrm{MJ} \mathrm{m}^{-2}\right)\end{array}$ \\
\hline 1 & Como & 198 & 145.91 & 22.5 & 410.0 & 154.0 & 11.7 & 12.1 & 4975 & 6274 & 1280 \\
\hline 2 & Maggiore & 194 & 212.51 & 37.5 & 370.0 & 176.5 & 14.6 & 14.6 & 4652 & 5970 & 1289 \\
\hline 3 & Garda & 65 & 367.94 & 49.031 & 350.0 & 133.3 & 34.3 & 19.2 & 4457 & 5919 & 1482 \\
\hline 4 & Lugano NB & 271 & 27.50 & 4.69 & 288.0 & 171.5 & 5.5 & 5.2 & 3484 & 4513 & 1029 \\
\hline 5 & Iseo & 186 & 60.94 & 7.57 & 258.0 & 124.2 & 9.2 & 7.8 & 3415 & 4264 & 850 \\
\hline 6 & Bracciano & 164 & 57.02 & 5.053 & 165.0 & 88.6 & 9.1 & 7.6 & 3048 & 4332 & 1284 \\
\hline 7 & Bolsena & 305 & 113.55 & 9.2 & 151.0 & 81.0 & 12.9 & 10.7 & 2512 & 3649 & 1137 \\
\hline 8 & Orta & 290 & 18.02 & 1.25 & 143.0 & 69.4 & 5.8 & 4.2 & 1614 & 2560 & 946 \\
\hline 9 & Idro & 368 & 11.50 & 0.684 & 120.5 & 59.5 & 5.1 & 3.4 & 1792 & 2655 & 834 \\
\hline 10 & Lugano FG & 271 & 20.30 & 1.14 & 95.0 & 56.2 & 5.2 & 4.5 & 1064 & 2000 & 936 \\
\hline 11 & Mergozzo & 194 & 1.83 & 0.083 & 73.0 & 45.4 & 1.7 & 1.4 & 1033 & 1858 & 995 \\
\hline 12 & Lugano PT & 271 & 1.10 & 0.03 & 50.0 & 27.3 & 1.4 & 1.0 & 629 & 1792 & 1163 \\
\hline 13 & Vico & 510 & 12.08 & 0.26 & 48.5 & 21.5 & 4.9 & 3.5 & 603 & 1510 & 920 \\
\hline 14 & Caldonazzo & 448 & 5.63 & 0.149 & 49.0 & 26.5 & 3.8 & 2.4 & 468 & 1389 & 921 \\
\hline 15 & Monate & 266 & 2.51 & 0.0453 & 34.5 & 18.1 & 2.1 & 1.6 & 234 & 980 & 745 \\
\hline 16 & Nemi & 320 & 1.79 & 0.031 & 32.4 & 17.0 & 1.6 & 1.3 & 498 & 1123 & 625 \\
\hline 17 & Varese & 238 & 14.95 & 0.162 & 26.0 & 10.9 & 5.8 & 3.9 & 167 & 769 & 655 \\
\hline 18 & Pusiano & 259 & 4.93 & 0.069 & 24.3 & 14.0 & 3.2 & 2.2 & 215 & 800 & 588 \\
\hline 19 & Oggiono & 224 & 3.81 & 0.024 & 11.3 & 6.3 & 2.5 & 2.0 & 63 & 565 & 502 \\
\hline 20 & Endine & 334 & 2.34 & 0.012 & 9.4 & 5.1 & 1.6 & 1.5 & 77 & 491 & 412 \\
\hline 21 & Segrino & 374 & 0.38 & 0.0012 & 8.6 & 3.2 & 1.0 & 0.6 & 38 & 292 & 250 \\
\hline 22 & Alserio & 260 & 1.23 & 0.007 & 8.1 & 5.4 & 1.5 & 1.1 & 50 & 406 & 356 \\
\hline 23 & Candia & 226 & 1.52 & 0.0072 & 7.7 & 4.7 & 1.5 & 1.2 & 57 & 384 & 331 \\
\hline 24 & Comabbio & 243 & 3.58 & 0.0164 & 7.7 & 4.6 & 2.5 & 1.9 & 94 & 454 & 360 \\
\hline 25 & Montorfano & 397 & 0.46 & 0.002 & 6.8 & 4.3 & 0.9 & 0.7 & 35 & 393 & 359 \\
\hline 26 & Canzolino & 540 & 0.07 & 0.0007 & 15.0 & 9.7 & 0.3 & 0.3 & 74 & 462 & 387 \\
\hline 27 & Frassino & 74 & 0.31 & 0.0024 & 15.0 & 6.9 & 0.7 & 0.6 & 141 & 612 & 471 \\
\hline 28 & Annone West & 224 & 1.70 & 0.007 & 10.1 & 4.1 & 1.8 & 1.3 & 39 & 410 & 371 \\
\hline 29 & Campagna & 237 & 0.13 & 0.0004 & 5.0 & 3.2 & 0.5 & 0.4 & 50 & 265 & 216 \\
\hline 30 & Michele & 241 & 0.07 & 0.0006 & 18.5 & 8.7 & 0.4 & 0.3 & 127 & 594 & 467 \\
\hline 31 & Nero & 305 & 0.13 & 0.0016 & 27.0 & 12.7 & 0.4 & 0.4 & 254 & 769 & 515 \\
\hline
\end{tabular}

heat budgets which are less subject to variations than those in maritime regions (Hutchinson 1957; Timms 1975), so that any sampling time errors are minimal.

Although the years for which the energy quantities in the 31 lakes were determined are not always the same, they can always be compared with the values for Lago Maggiore, which span a long period of time (around 40 years). The overall picture of the measurement data available is the one included in the study by Pompilio et al. (1996), updated to 1999; this shows, for each lake, the years for which data of water temperatures are available, as well as the bibliographic references and the number of profiles considered.

\section{RESULTS}

\subsection{Correlation of investigated parameters}

The parameters of the 31 studied lakes were normalised by means of a logarithmic transformation, or a square or cubic root. Correlation matrices refer both to the entire lake assemblage and to groups of deep and shallow lakes (the separation limit was set at $\mathrm{z}_{\max }=50$ $\mathrm{m})$.

Considering the entire assemblage of 31 lakes, we found a strong relationship between the maximum and minimum heat contents and the heat budget with the morphometric parameters, especially with maximum and mean depth, the depths of percentage heat exchange, and volume ( $\mathrm{r}$ between 0.93 and 0.99) (Tab. 2A).

Considering only the deep lakes (Tab. 2B), there is a marked correlation between $Q_{t \max }, Q_{\operatorname{tmin}}$ with $Z_{\max }$ and $\mathrm{Z}_{\min }$; in contrast, $\mathrm{B}_{\mathrm{t}}$ presents its highest $\mathrm{r}$ with $\mathrm{F}_{\text {area }}, \mathrm{F}_{\text {eff }}$ and $z_{50}$ and $z_{90}(p<0.001)$, and with depth only at a level of $p<0.1$. Interestingly, in the group of shallower lakes (Tab. 2C) there is no relationship between fetch and $\mathrm{B}_{\mathrm{t}}$, while this is very high with the other depths.

\subsection{Temporal variability}

We selected the 10 lakes for which we had more than five years of heat budget and heat content data; in spite of the limited number, these include the whole morphometric range of Italian lakes, from the shallowest to the deepest.

\subsubsection{Heat budget}

The interannual coefficients of variation $(\mathrm{CV})$ of $\mathrm{B}_{\mathrm{t}}$ in table 3 show similar values for the deep, high volume lakes like Maggiore (CV=9.9\%), Garda (9.2\%), Orta $(8.5 \%)$ as well as for the smaller lakes Varese $(9.2 \%)$ and Endine (9.5\%). In contrast, CV are very low in the small Lake Candia (2.1\%), in Lake Mergozzo (2.6\%), and the deepest lake in Italy, Lake Como (410 m), with a value of $5.9 \%$. 
Tab. 2. Correlation matrix of morphometric variables and energy parameters for all (A), deep (B) and shallow (C) lakes.

\begin{tabular}{|c|c|c|c|c|c|c|c|c|c|c|c|c|c|}
\hline \multicolumn{14}{|c|}{$\mathbf{A}$} \\
\hline & $\mathrm{V}$ & $\mathrm{z}_{\max }$ & $\mathrm{F}_{\text {area }}$ & $F_{\text {eff }}$ & $\mathrm{Z}_{\text {mean }}$ & A & $\mathrm{z}_{\mathrm{epi}}$ & $\mathrm{z}_{\text {term }}$ & $\mathrm{Q}_{\mathrm{t} \max }$ & $\mathrm{B}_{\mathrm{t}}$ & $\mathrm{Q}_{\mathrm{t} \min }$ & $\mathrm{z}_{90}$ & $\mathrm{z}_{50}$ \\
\hline V & 1.00 & & & & & & & & & & & & \\
\hline $\mathrm{Z}_{\max }$ & 0.92 & 1.00 & & & & & & & & & & & \\
\hline $\mathrm{F}_{\text {area }}$ & 0.97 & 0.81 & 1.00 & & & & & & & & & & \\
\hline $\mathrm{F}_{\text {eff }}$ & 0.96 & 0.79 & 0.99 & 1.00 & & & & & & & & & \\
\hline $\mathrm{z}_{\mathrm{med}}$ & 0.92 & 0.99 & 0.80 & 0.78 & 1.00 & & & & & & & & \\
\hline A & 0.97 & 0.81 & 1.00 & 0.99 & 0.80 & 1.00 & & & & & & & \\
\hline$z_{\mathrm{epi}}$ & 0.74 & 0.72 & 0.71 & 0.72 & 0.70 & 0.71 & 1.00 & & & & & & \\
\hline $\mathrm{Z}_{\text {term }}$ & 0.86 & 0.86 & 0.82 & 0.81 & 0.83 & 0.82 & 0.92 & 1.00 & & & & & \\
\hline $\mathrm{Q}_{\mathrm{t} \max }$ & 0.94 & 0.99 & 0.84 & 0.82 & 0.99 & 0.84 & 0.75 & 0.88 & 1.00 & & & & \\
\hline $\mathrm{B}_{\mathrm{t}}$ & 0.88 & 0.93 & 0.78 & 0.77 & 0.93 & 0.78 & 0.78 & 0.91 & 0.95 & 1.00 & & & \\
\hline $\mathrm{Q}_{\mathrm{t} \text { min }}$ & 0.91 & 0.98 & 0.80 & 0.78 & 0.98 & 0.80 & 0.70 & 0.85 & 0.99 & 0.93 & 1.00 & & \\
\hline $\mathrm{Z}_{90}$ & 0.92 & 0.96 & 0.83 & 0.82 & 0.95 & 0.83 & 0.78 & 0.90 & 0.97 & 0.98 & 0.95 & 1.00 & \\
\hline $\mathrm{z}_{50}$ & 0.90 & 0.95 & 0.81 & 0.80 & 0.94 & 0.81 & 0.77 & 0.90 & 0.97 & 0.97 & 0.95 & 0.98 & 1.00 \\
\hline
\end{tabular}

B

\begin{tabular}{|c|c|c|c|c|c|c|c|c|c|c|c|c|c|}
\hline & V & $\mathrm{Z}_{\max }$ & $\mathrm{F}_{\text {area }}$ & $\mathrm{F}_{\text {eff }}$ & $\mathrm{Z}_{\text {mean }}$ & A & $Z_{\mathrm{epi}}$ & $z_{\text {term }}$ & $\mathrm{Q}_{\mathrm{t} \max }$ & $\mathrm{B}_{\mathrm{t}}$ & $\mathrm{Q}_{\mathrm{t} \text { min }}$ & $\mathrm{z}_{90}$ & $\mathrm{z}_{50}$ \\
\hline $\mathrm{V}$ & 1 & & & & & & & & & & & & \\
\hline $\mathrm{z}_{\max }$ & 0.87 & 1.00 & & & & & & & & & & & \\
\hline$F_{\text {area }}$ & 0.98 & 0.75 & 1.00 & & & & & & & & & & \\
\hline $\mathrm{F}_{\text {eff }}$ & 0.89 & 0.63 & 0.95 & 1.00 & & & & & & & & & \\
\hline $\mathrm{Z}_{\mathrm{med}}$ & 0.81 & 0.96 & 0.66 & 0.51 & 1.00 & & & & & & & & \\
\hline A & 0.98 & 0.75 & 1.00 & 0.95 & 0.66 & 1.00 & & & & & & & \\
\hline $\mathrm{Z}_{\mathrm{epi}}$ & 0.60 & 0.34 & 0.65 & 0.65 & 0.31 & 0.65 & 1.00 & & & & & & \\
\hline $\mathrm{z}_{\text {term }}$ & 0.70 & 0.42 & 0.76 & 0.74 & 0.36 & 0.76 & 0.96 & 1.00 & & & & & \\
\hline $\mathrm{Q}_{\mathrm{t} \max }$ & 0.92 & 0.95 & 0.84 & 0.73 & 0.91 & 0.84 & 0.57 & 0.66 & 1.00 & & & & \\
\hline $\mathrm{B}_{\mathrm{t}}$ & 0.82 & 0.60 & 0.84 & 0.81 & 0.53 & 0.84 & 0.78 & 0.86 & 0.74 & 1.00 & & & \\
\hline $\mathrm{Q}_{\mathrm{t} \text { min }}$ & 0.89 & 0.95 & 0.79 & 0.69 & 0.91 & 0.79 & 0.53 & 0.61 & 0.99 & 0.67 & 1.00 & & \\
\hline $\mathrm{z}_{90}$ & 0.85 & 0.61 & 0.90 & 0.81 & 0.51 & 0.90 & 0.65 & 0.78 & 0.75 & 0.91 & 0.68 & 1.00 & \\
\hline $\mathrm{z}_{50}$ & 0.86 & 0.67 & 0.91 & 0.91 & 0.51 & 0.91 & 0.61 & 0.75 & 0.78 & 0.87 & 0.73 & 0.93 & 1.00 \\
\hline
\end{tabular}

\begin{tabular}{|c|c|c|c|c|c|c|c|c|c|c|c|c|c|}
\hline \multicolumn{14}{|c|}{ C } \\
\hline & $\mathrm{V}$ & $\mathrm{z}_{\max }$ & $\mathrm{F}_{\text {area }}$ & $\mathrm{F}_{\text {eff }}$ & $\mathrm{z}_{\text {mean }}$ & A & $\mathrm{z}_{\mathrm{epi}}$ & $z_{\text {term }}$ & $\mathrm{Q}_{\mathrm{t} \max }$ & $\mathrm{B}_{\mathrm{t}}$ & $\mathrm{Q}_{\mathrm{t} \min }$ & $\mathrm{Z}_{90}$ & $\mathrm{z}_{50}$ \\
\hline V & 1.00 & & & & & & & & & & & & \\
\hline$Z_{\max }$ & 0.46 & 1.00 & & & & & & & & & & & \\
\hline$F_{\text {area }}$ & 0.95 & 0.18 & 1.00 & & & & & & & & & & \\
\hline $\mathrm{F}_{\mathrm{eff}}$ & 0.93 & 0.16 & 0.99 & 1.00 & & & & & & & & & \\
\hline$z_{\operatorname{med}}$ & 0.47 & 0.95 & 0.17 & 0.14 & 1.00 & & & & & & & & \\
\hline A & 0.95 & 0.18 & 1.00 & 0.99 & 0.17 & 1.00 & & & & & & & \\
\hline $\mathrm{Z}_{\mathrm{epi}}$ & 0.43 & 0.42 & 0.35 & 0.35 & 0.37 & 0.35 & 1.00 & & & & & & \\
\hline $\mathrm{z}_{\text {term }}$ & 0.67 & 0.76 & 0.50 & 0.49 & 0.67 & 0.50 & 0.76 & 1.00 & & & & & \\
\hline $\mathrm{Q}_{\mathrm{t} \max }$ & 0.61 & 0.94 & 0.34 & 0.30 & 0.93 & 0.34 & 0.43 & 0.79 & 1.00 & & & & \\
\hline$B_{t}$ & 0.67 & 0.90 & 0.43 & 0.39 & 0.90 & 0.43 & 0.44 & 0.80 & 0.97 & 1.00 & & & \\
\hline $\mathrm{Q}_{\mathrm{t} \min }$ & 0.44 & 0.89 & 0.18 & 0.14 & 0.90 & 0.18 & 0.17 & 0.59 & 0.92 & 0.83 & 1.00 & & \\
\hline $\mathrm{z}_{90}$ & 0.67 & 0.92 & 0.44 & 0.42 & 0.88 & 0.44 & 0.47 & 0.80 & 0.91 & 0.92 & 0.79 & 1.00 & \\
\hline $\mathrm{Z}_{50}$ & 0.62 & 0.91 & 0.37 & 0.33 & 0.91 & 0.37 & 0.50 & 0.81 & 0.96 & 0.94 & 0.85 & 0.96 & 1.00 \\
\hline
\end{tabular}

For some lakes we have data sets only for a period of 3-4 years and are merely indicative. The CV values of the respective heat budgets differed even more: for example, $4.5 \%$ for Lugano FG (95 m deep), 11.2\% for Lake Annone, $(10 \mathrm{~m}), 12.6 \%$ for Lake Idro $(120 \mathrm{~m})$ and $7.9 \%$ for Lake Vico (48.5 m).

Timms' (1975) conclusion, after his evaluation of the interannual $\mathrm{CV}$ of lakes in various parts of the world, is that the $\mathrm{B}_{\mathrm{t}}$ variation in a lake is mainly controlled by its morphometry, with greater variability in the larger lakes. Bowling \& Salonen (1990) found an interannual $\mathrm{CV}$ of $\mathrm{B}_{\mathrm{t}}$ in Lake Nimeton of $14.7 \%$, which is not consistent with Timms' findings (1975). They assume that this lake was too small for morphometric control to be effective.

The Italian lakes do not display the tendency, recorded by Timms (1975), for larger basins to have a greater interannual variation in their heat budgets than smaller lakes.

Furthermore, in our lakes the interannual $\mathrm{CV}$ of heat budgets range from 2.1 to 11.8 , a much more restricted range than the values reported by Timms (1975) (between 1.9 and 38.4); this is because the Italian lakes are all at around the same latitude and, unlike the lakes in Timms' study, belong to only two climatic districts, and even those are quite similar. 
Our findings do not reveal any apparent relationship between the $\mathrm{CV}$ of the heat budgets and morphometric size alone; what seem to be important are the shape of the lake and the potential fetch, so that elongated lakes have higher CVs than round ones such as Candia, Mergozzo and Lugano PT.

Tab. 3. Interannual coefficients of variation (CV) for the heat budget $\left(\mathrm{B}_{\mathrm{t}}\right)$ and minimum and maximum heat content $\left(\mathrm{Q}_{\mathrm{t} \min }, \mathrm{Q}_{\mathrm{t} \max }\right)$ in selected Italian lakes.

\begin{tabular}{lccccc}
\hline \multirow{2}{*}{ Lake } & \multirow{2}{*}{$\begin{array}{c}\mathrm{Z}_{\max } \\
(\mathrm{m})\end{array}$} & years & \multicolumn{3}{c}{$\mathrm{CV}$} \\
\cline { 4 - 6 } & & $\mathrm{B}_{\mathrm{t}}$ & $\mathrm{Q}_{\mathrm{t} \text { min }}$ & $\mathrm{Q}_{\mathrm{t} \max }$ \\
\hline Como & 410 & 10 & 5.9 & 5.1 & 4.3 \\
Maggiore & 370 & 40 & 9.9 & 3.4 & 3.4 \\
Garda & 350 & 10 & 9.2 & 2.3 & 2.3 \\
Orta & 143 & 20 & 11.8 & 7.0 & 5.8 \\
Mergozzo & 73 & 5 & 2.6 & 10.9 & 4.0 \\
Varese & 26 & 5 & 9.2 & 9.2 & 5.3 \\
Endine & 9.4 & 12 & 9.5 & 27.4 & 6.0 \\
Candia & 6.5 & 8 & 2.1 & 5.5 & 2.4 \\
Lugano FG & 95 & $3-4$ & 4.5 & & \\
Vico & 48.3 & $3-4$ & 8.0 & 10.1 & 7.2 \\
Lugano PT & 50 & $3-4$ & 4.0 & 3.7 & 6.9 \\
Oggiono & 11.3 & $3-4$ & 8.9 & & \\
Idro & 120 & $3-4$ & 12.6 & 4.5 & 9.1 \\
Annone W & 10 & $3-4$ & 11.2 & & \\
S. Parmense & 22 & $3-4$ & 9.8 & 19.5 & 7.7 \\
\hline
\end{tabular}

The influence of a lake's shape on the depth of the thermocline and the thickness of the epilimnion was demonstrated for Italian lakes by Pompilio et al. (1996). We therefore conclude that the interannual variability of heat budgets does not depend exclusively on the passive (morphometric) components alone, but on an integration of these with the active components, in particular with exposure and/or protection from the wind and with other climatic factors such as the energetic components of the heat budget, which also play a major part.

\subsubsection{Heat content}

An analysis of the interannual $\mathrm{CV}$ of the maximum and minimum heat contents revealed that the coefficients of variation in summer are restricted in range, from 2.3 to 5.9 , while their winter values have a much broader range (from 2.3 to 27.4), in spite of the fact that measurement errors are potentially greater in the warmest period. In particular, the interannual variability of heat content in the deepest lakes (Como, Garda, Maggiore and Orta) is almost identical in winter and in summer. It follows that a winter with minimum $\mathrm{Q}_{t}$ does not necessarily correspond to a summer with low $\mathrm{Q}_{\mathrm{t}}$, or vice versa. The exchanges of radiation and mass occurring between the atmosphere and the water in winter thus take on major importance, as they determine the depth of mixing and consequently the heat loss by the lake, the inflow depth of tributary waters in March-May, snow/ ice-melt months and the efficiency of heat distribution by the wind within the surface layer in summer.
In contrast, the $\mathrm{CV}$ of minimum heat content is generally higher in the shallow lakes than in the deep ones, and in the shallow lakes the $\mathrm{CV}$ is higher in winter than in summer. This is due to the fact that small basins are particularly sensitive to variations in the winter climate. For example, Lake Endine may be partially ice covered in winter, while this is extremely rare in large lakes at our latitudes because of their heat capacity.

\subsection{Regional variability of heat content}

As discussed above, the quantity of internal energy present in our lakes is closely dependent on their morphology; in particular, the parameters which show the highest correlation with heat content are $z_{\max }$ and $z_{\text {mean }}$.

Figure 2 shows the two curves $\mathrm{Q}_{\operatorname{tmax}}$ and $\mathrm{Q}_{\operatorname{tmin}}$ correlated with the maximum depth of each lake. In spite of the excellent correlation $\left(\mathrm{r}^{2}=0.97-0.98\right)$, some lakes deviate from the curve, and therefore their particular environmental conditions are described. For instance, it is well-known that shallow lakes are very sensitive to their local microclimate, more so than deep lakes, which may in turn be strongly affected by their internal hydrodynamics.

The lakes in the coastal region of Lazio, i.e. Vico, Bolsena, Bracciano and Nemi, have a higher heat content (in particular $\mathrm{Q}_{\text {tmin }}$ ) than might be expected from their depth.

The greater energy input of these lakes clearly derives from the distinctive meteorological situation of the region of Lazio, in particular regarding solar radiation and wind, i.e. the quantity of heat available and the force which can distribute it to the bottom. The solar radiation in the low latitudes of Central Italy is much higher than that of the northern part of the Po Plain and the southern edge of the Alps, where all the other lakes are located. In addition, the lakes in Lazio are influenced by moderate sea breezes blowing from W-SW (Pompilio et al. 1996), typically occurring every afternoon. In contrast, the heat losses during the winter are lower than in lakes of equal depth in the north of Italy.

The small, round Lugano PT also presents $Q_{t}$ higher than might be expected, but this is probably due to its hydrography. There is inflow of warm surface water from Lugano FG, which increases the thickness of the mixed layer where the major energy exchange occurs; this gives rise to a deeper epilimnion and therefore a higher heat content.

Lake Mergozzo is another lake where the heat content exceeds expectations; this is probably due to the thermocline having a greater depth than was expected from the results of the predictive model devised by Pompilio et al. (1996) for round lakes. This lake is located at the mouth of the major valley of the River Toce, where the intensity of the wind can be very high.

The $\mathrm{Q}_{\mathrm{t}}$ of the three great Italian lakes, Garda, Como and Maggiore, is perfectly in line with the trend of the power equation. The $\mathrm{Q}_{\operatorname{tmax}}$ of Garda is slightly higher, 


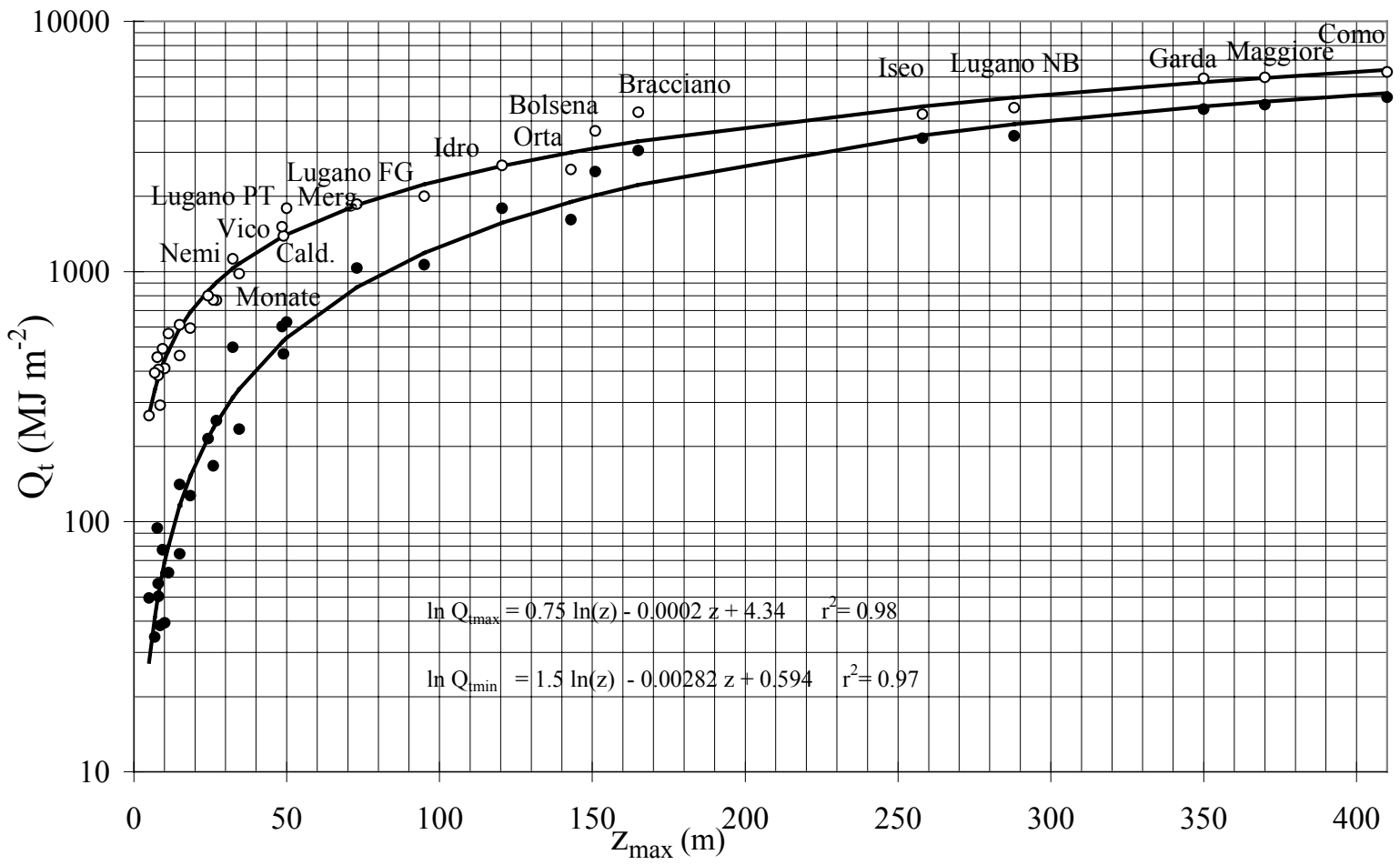

Fig. 2. Relationship of maximum (o) and minimum $(\bullet)$ heat content $\left(\mathrm{Q}_{\mathrm{t}}\right)$ to $\mathrm{z}_{\max }$ in 31 Italian lakes.

undoubtedly on account of its great surface area which enables the lake to absorb a large quantity of heat and distribute it to the deepest layers, driven by the wind: in fact, of the great lakes, it is Garda that has the highest temperatures along the column. This is also confirmed by the fact that in the correlation matrix referring only to deep lakes, the $r$ value between $Q_{t}$ and the surface area increases considerably. Como is the Italian lake with the highest mean heat content; besides its greater depth, it has the typical shape of a valley lake - long, narrow and deeply set into the surrounding mountains so that winds blowing along the main axis, which can be very strong, are decisive in the process of surface heat accumulation.

Two basins of Lake Lugano, Lugano NB and Lugano FG, have a heat content that is lower than the potential. Like Como and Maggiore, they are typical valley lakes, but unlike them the two basins are highly conditioned by the hydro-meteorological situation and by their prevalently east-west morphometrical alignment. The scarcity of wind and their shape, like a backto-front $\mathrm{S}$, cut the fetch by half, especially in Lugano $\mathrm{FG}$, and determine a low distribution of heat, a situation confirmed by the shallow depth of the thermocline (Ambrosetti et al. 1996). In addition, their state of meromixis, which only partially affects Lugano FG but is more evident in Lugano NB, means that their hydrodynamic behaviour is highly unusual, so that they may be considered as shallower than they actually are.
Orta and Iseo also fall below the curves; in their case, unlike that of Lake Mergozzo, the explanation lies in the limited thickness of the mixed layer. Lake Idro is another anomalous case, comparable to the two Lugano basins on account of its meromixis.

Finally, in small lakes, where low $\mathrm{z}_{\max }$ variations can correspond to great variations in $\mathrm{Q}_{\mathrm{t}}$, climatic conditions may determine the lakes' position on the graph. This is the case in some lakes which are morphometrically similar, like Monate and Nemi. In other cases, where the mean depth is similar, variations on the graph may derive from volume and surface area, depth of epilimnion or thermocline, or the advective budget or the depth and type of inflow from the tributaries, as can be observed in a comparison between the Caldonazzo and Lugano PT. For example, one of the small lakes with a negative deviation from the curve is Canzolino, whose position is the result of a concurrence of factors: its high altitude, its smaller surface area and greater mean depth compared to other small lakes.

\subsection{Regional variability of heat budget}

The heat budget, i.e. the difference between the two heat quantities $\left(\mathrm{Q}_{\operatorname{tmax}}\right.$ and $\left.\mathrm{Q}_{\mathrm{tmin}}\right)$ described in the last section, represents the capacity of a lake to store energy during the year, and may be regarded as the synthesis of all the physical processes occurring at the air-water interface and within the water mass. It is strongly influenced by morphometric parameters. Gorham (1964) 


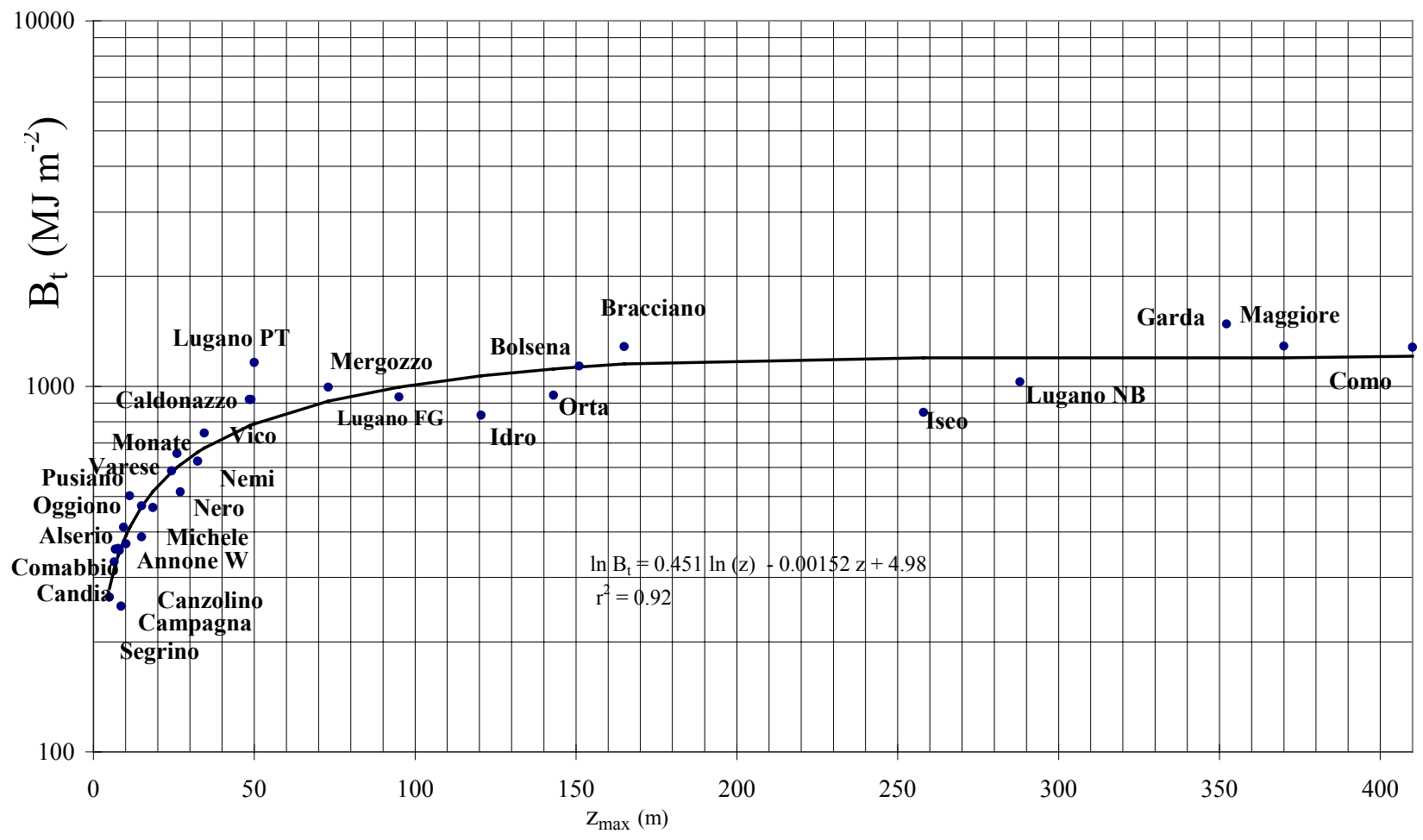

Fig. 3. Relationship of heat budgets $\left(B_{t}\right)$ and $z_{\max }$ in 31 Italian lakes.

found that the heat budget of a lake is most closely related to its volume, while for Geller (1992) surface area was the most important parameter; Schindler (1971) and Allot (1986) found mean depth to be the determining factor.

Table 2 shows that the morphometric parameters most closely correlated with the heat budget are, to an equal degree, mean and maximum depth. The relationship of $z_{\max }$ with the heat budget $\left(B_{t}\right)$ is shown in figure 3 , where there is some dispersion of the points around the curve of best fit, especially for those referring to deep lakes; this involves a value of determination coefficient $\left(\mathrm{r}^{2}=0.92\right)$ lower than those relating to the curves in figure 1.

The correlation matrices relating separately to deep and shallow lakes show that in the deep lakes (Tab. 2B) there is no significant correlation between the heat budget and maximum and mean depths, while this correlation is very high in the shallow lakes (Tab. 2C). This may be attributed to the different relative thickness of the water layer affected by the annual heat exchange, which can be close to $z_{\max }$ for shallow lakes, but is small for lakes with $\mathrm{z}_{\max }>100 \mathrm{~m}$.

In the deep lakes, the relationship between $B_{t}$ and fetch, the latter understood both as effective length and square root of the surface area, is highly significant, but it is not found in the shallow lakes.
This contrast is due to the fact that the shallow lakes, though strictly speaking belonging to the category of three-layer structures according to the model of Barbanti et al. (1996), which describes the type of summer thermal stratification developing in a single lake, are very close to the 0.5 value line indicating a two-layer system in this model. Hence, in summer, shallow lakes develop an vertical thermal structure formed only of an epilimnion and a metalimnion, which can easily be fully mixed when there is wind, not necessarily strong. Their shallow depth, together with an unstable epilimnion, means that a relatively light, steady wind can distribute the heat from the surface layers down to the bottom of the basin, or close to it. This causes a lowering of the thermocline close to the bottom of the lake and the "deep" water can thus take part in the heat exchange. In contrast, very deep lakes like Como or Lugano FG have a completely different internal hydrodynamic situation: they are holo-oligomictic and develop a system that can correspond to a four-layer model (Ambrosetti \& Barbanti 1999; Ambrosetti \& Barbanti 2000), with high stability and a $Z_{\max }$ which is at least 20 times greater than that of the epilimnion. Hence, the downward transport of heat, limited to a well-defined layer of the lake, requires wind conditions able to exercise an intense stress on the lake surface. Therefore, the heat budget of deep lakes is not significantly correlated with 


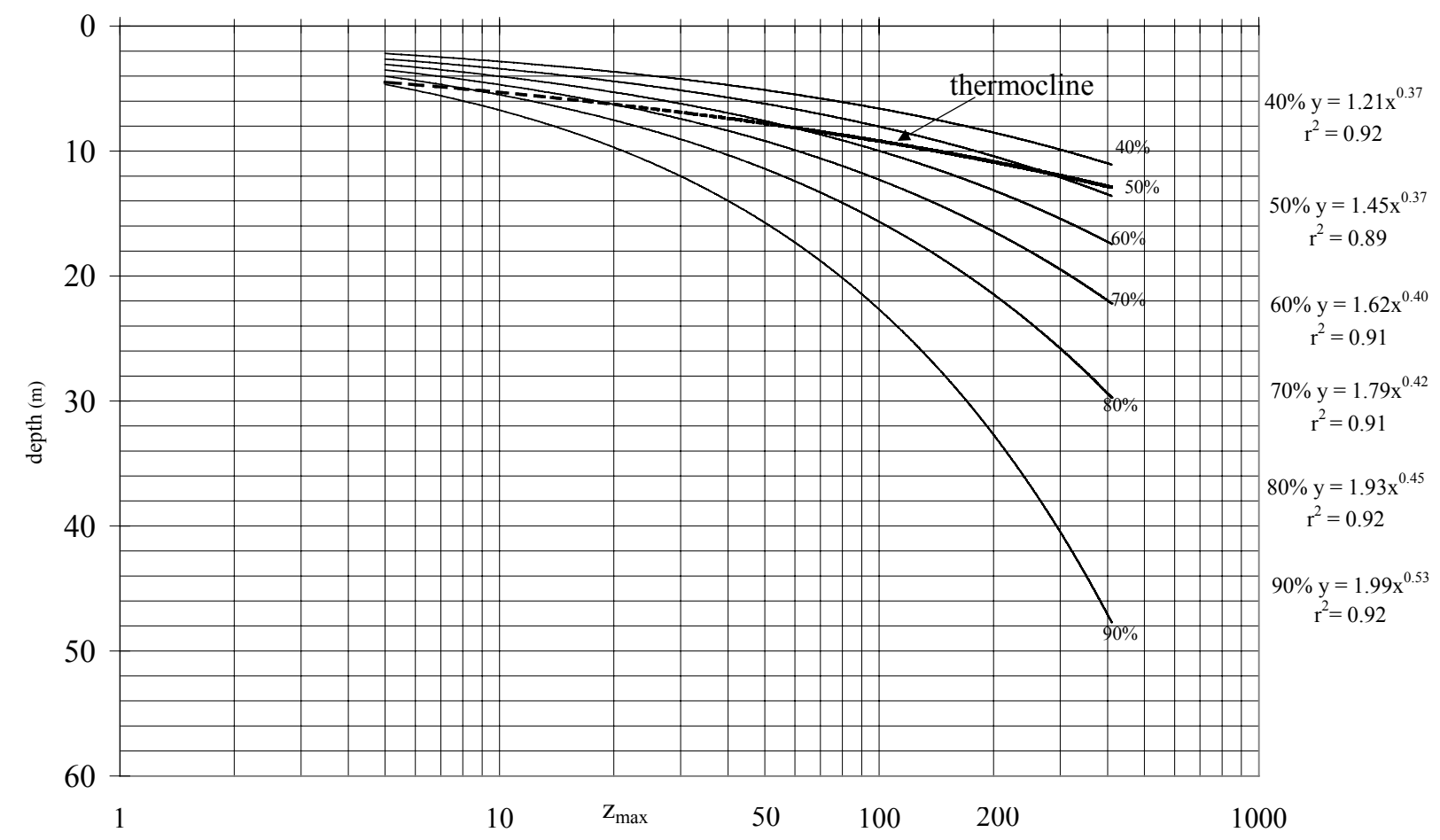

Fig. 4. Depths of percentages of annual heat exchange and depth of thermocline for the period July to August in 31 Italian lakes.

$\mathrm{Z}_{\max }$ and $\mathrm{z}_{\text {mean }}$, but the correlation is significant (to the level of $\mathrm{p}<0.001$ ) with surface area and fetch.

In lakes deeper than $100 \mathrm{~m}$ the influence of climate on the heat budget is expected to be greater than that of morphometry, while in shallow lakes morphometry (essentially depth) is predominant.

\subsection{Percentage of energy exchange}

The most important morphometric parameter for understanding the heating of a lake and the processes of heat exchange within lakes is the depth at which a certain percentage of energy exchange occurs during the year.

The vertical curves of heat percentage exchange were used to determine the water thicknesses within which 40 to $90 \%$ of the total energy exchanges occur (Fig. 4). The results show that in the deep lakes $90 \%$ of the annual energy exchange takes place within a surface layer representing only $14-16 \%$ of the maximum depth. The deepest parts of these lakes are thus involved only to a very limited extent in the heat exchange in the course of a year, while in the shallow lakes the same percentage of heat exchange can involve as much as $82 \%$ of the $\mathrm{Z}_{\max }$ (Fig. 4) . Power regressions of each heat exchange and depth obtained from the experimental data revealed a correlation coefficient of $r^{2}>0.90$. The increase in the exponent is relatively low compared with the coefficient, of each function and it is this which has a greater impact on the thickness of the water layers involved in the heat exchange; the increase in heat ex- change in deep lakes is greater as the energy exchange percentage increases, but is proportionally lower than that of shallow lakes, if considered in relation to the maximum depth

Figure 3 also shows the mean depth of the thermocline for the period July-August in the same 31 Italian lakes. In shallow lakes the thermocline coincides almost exactly with the $90 \%$ heat exchange depth, while it stays between the 50 and $60 \%$ curve in lakes of depths between 60 and $270 \mathrm{~m}$, and remains above the $50 \%$ heat exchange curve in lakes deeper than $300 \mathrm{~m}$. Hence, in lakes with a depth $>100 \mathrm{~m}$, more than half of the heat exchange occurs below the thermocline, showing that the thermocline does not represent an absolute heat barrier, and that the quantities of energy involved affect a layer which in deep lakes is 3-4 times the depth of the thermocline. The annual heat exchange therefore consistently affects more than a third of the "superficial hypolimnion", as defined in Michalsky \& Lemmin (1995), Ambrosetti \& Barbanti (1999) and Ambrosetti \& Barbanti (2000). The relationship between heat budget and lake volume (Tab. 2) for the 31 selected lakes is summarised in figure 5.

In Lake Como, the deepest Italian lake, $90 \%$ of $\mathrm{B}_{\mathrm{t}}$, is exchanged within only $25 \%$ of the lake's volume, whereas in the shallow lakes more than $90 \%$ of the lake's volume is involved in this exchange. However, there are some anomalous situations which can be explained only by examining the specific characteristics of the individual lakes. 


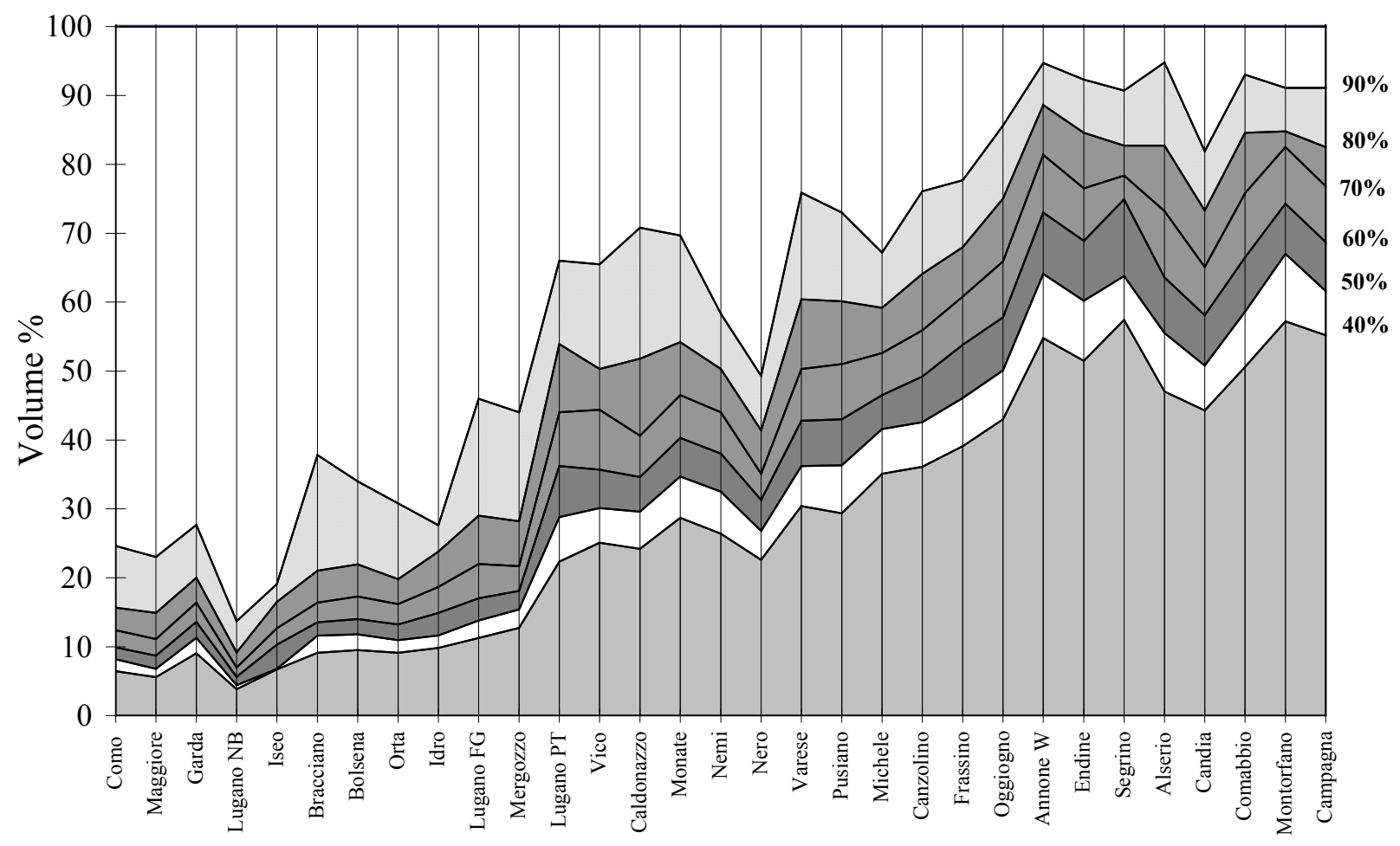

Fig. 5. Relationship between annual heat exchange percentage (40 to 90\%) and volume percentage of lake water involved. The lakes are in decreasing order of maximum depth.

Of the deep lakes, Lugano North and Idro present a marked reduction of the water thicknesses involved in heat exchanges; this confirms our previous observation about their $\mathrm{Q}_{\operatorname{tmax}}$ and $\mathrm{Q}_{\mathrm{tmin}}$ in connection with their meromictic state. For this reason Lugano NB should be considered as around $100 \mathrm{~m}$ deep (depth of the chemocline), while Idro would not be deeper than $50 \mathrm{~m}$, which would change their position in figure 4 .

The same observations could be made about Lake Iseo which, despite having a very similar morphology to lakes Maggiore and Como, has a distinctive internal hydrodynamic situation, as regards winter mixing, deep oxygenation, and summer heating: in fact, it is in danger of meromixis due to the deterioration of its water in recent years (Garibaldi et al. 1997).

The anomalous situations of lakes Nero, Michele and Candia may be attributed to the inflow of cold water from underground springs at their deepest levels (Di Natale \& Durio 1993), causing a constant layer of heavier water at the bottom of the lakes which does not permit further deepening of the thermocline.

\subsection{Temporal variability}

The depths indicating the heat exchange percentages in the deep lakes are also subject to variations over the years, depending on the meteorological conditions affecting the lake area. For example, in Lago Maggiore the 50 and $90 \%$ depths, in the 37 years considered, present variation coefficients of 11.13 and 26.5 respectively, but as figure 5 shows, the general trend of the layer where $90 \%$ of the heat is exchanged is towards a deepening, which becomes more evident from the second half of the 70s, and even more so in the 80s. In 1988 there was again a reduction to only 30 metres, but in that year the summer wind reached its absolute minimum in the last 50 years (a wind run of only $2100 \mathrm{~km}$ in three months), creating difficulties for the transport of heat to the deeper waters.

Again in Lago Maggiore, from 1963 to 1999, the $50 \%$ exchange displayed a mean deepening of $0.029 \mathrm{~m}$ (total $1.05 \mathrm{~m}$ ), while the $90 \%$ exchange was greater, on average $0.34 \mathrm{~m}$ per year, with a total increase of $12.6 \mathrm{~m}$. This contributed to increasing the heat content in the lake, which rose from $5562 \mathrm{MJ} \mathrm{m}^{-2}$ in 1963 to $6448 \mathrm{MJ}$ $\mathrm{m}^{-2}$ in 1999.

The trend of these depths, which should be analysed in the light of the yearly variations in each meteorological parameter, in particular wind, atmospheric temperature, surface water temperature, and solar radiation (as was done for the mixing depths, Ambrosetti et al.1979), adapts to a polynomial curve which in Lago Maggiore has a 28 year cycle with a maximum and minimum exactly every 14 years; even though our historical series is quite short (37 years) (Fig. 6), this remains a very interesting fact. 


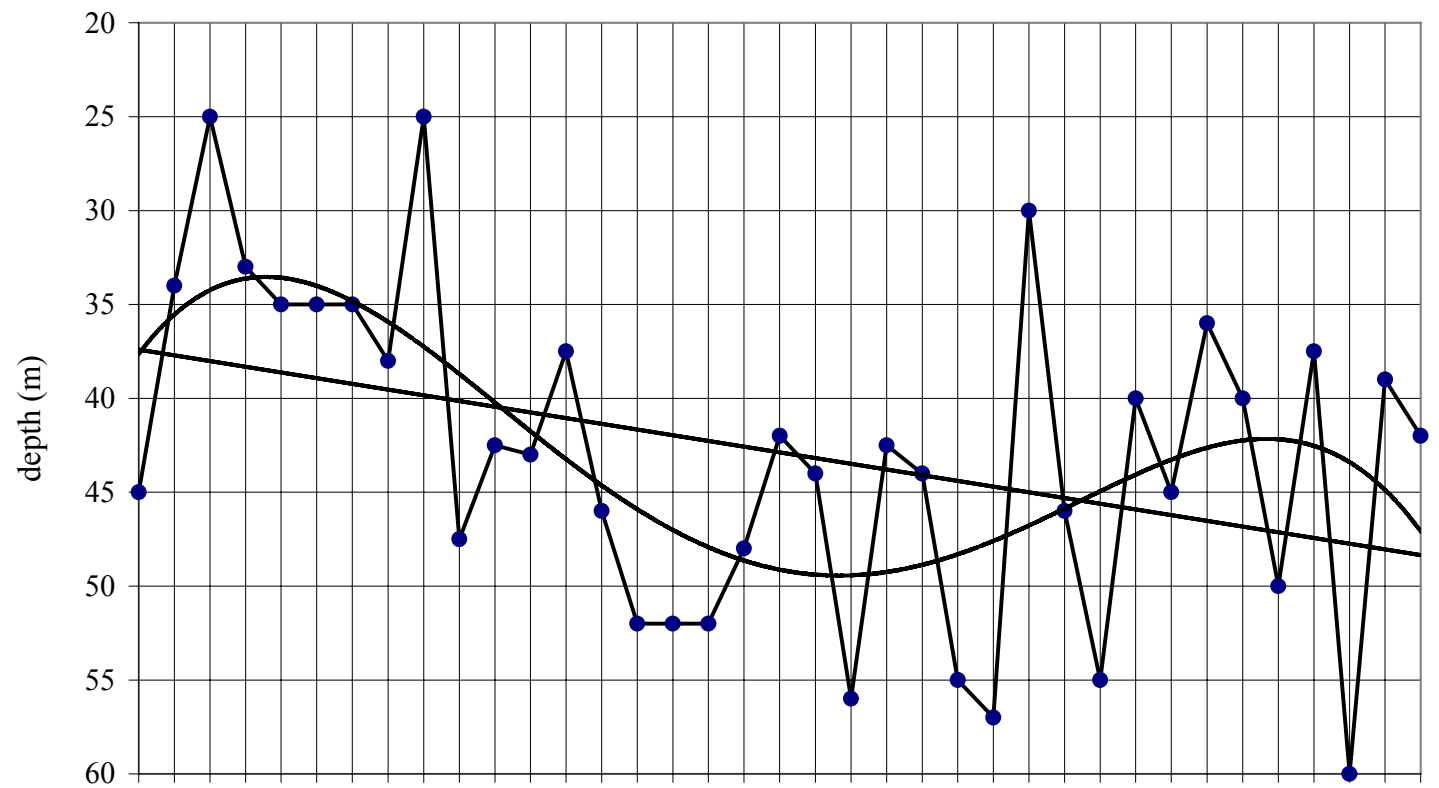

63646566676869707172737475767778798081828384858687888990919293949596979899

Fig. 6. Depth of 90\% heat exchange in Lago Maggiore from 1963 to 1999 including trend line and polynomial curve.

The lowering found in Lago Maggiore is also found in Lake Orta; the lowering of the $90 \%$ exchange layer in 1984-1999 was $2.22 \mathrm{~m}$ (0.138 m per year), resulting in a rise in the $\mathrm{Q}_{\mathrm{tmax}}$ from 2468 to $2959 \mathrm{MJ} \mathrm{m}^{-2}$, higher than the value for Lago Maggiore in the same period $(0.130$ $\mathrm{m})$.

\section{CONCLUSIONS}

The 31 lakes considered in this study include all of the deepest lakes in Italy, and a highly significant sample of the shallow ones. They are located in the two main Italian lake districts in the Sudalpine area and Lazio. Starting from their thermal characteristics, we evaluated their energy content and in particular their monthly heat content and their annual heat budget, using all the data available for each lake. For the whole set of lakes we found significant correlation between energy parameters and morphometry; if however the shallow lakes were considered separately from the deep ones, differences emerged in the significance of the correlation, partly due to morphometry and partly to meteoclimatic conditions.

The internal hydrodynamic mechanisms, which vary according to the shape of the lake and its exposure to external conditions, control the heat transport occurring within the water mass. In the deep lakes, not only is the mixed layer subject to heating, but the heat also goes beyond the barrier of the thermocline to affect what has been called the superficial hypolimnion. In the shallow lakes the whole volume of the water exchanges heat with the atmosphere.
Some lakes, both deep and shallow, are distinguished by particular conditions affecting their hydrology (e.g. Lake Bolsena) or their subterranean hydrology (Candia), the local microclimate (Mergozzo), distinctive morphological conditions (Garda), or their meromictic state (Idro). Due to the availability of long series of data for lakes Maggiore and Orta, we were able to verify the variations in time of the depth at which most of the heat has accumulated. This depth has continued to increase since the 70s, as has the depth of the thermocline, and together these phenomena have determined an increase in the heat content of these two lakes. It is clear that this is a consequence of the current process of global warming.

\section{REFERENCES}

Allot, N.A. 1986. Temperature, oxygen and heat-budget of six small western Irish lakes. Freshwat. Biol., 16: 145-154.

Ambrosetti, W.\& L. Barbanti. 1999. Deep water warming in lakes: an indicator of climate change. J. Limnol., 58(1): 19.

Ambrosetti, W.\& L. Barbanti. 2000. Riscaldamento delle acque profonde nei laghi italiani: un indicatore di cambiamenti climatici. Acqua \&Aria. $\mathrm{N}^{\circ} 4$ : 65-72.

Ambrosetti, W., L. Barbanti \& L.Pompilio.1996. Morphometry and thermal stratification in Italian lakes.3 Dynamic of the deepening of thermocline. Mem. Ist. ital. Idrobiol., 54: 43-50.

Ambrosetti, W., L. Barbanti \& A. Rolla. 1979. Mescolamento parziale o totale nel Lago Maggiore nell'ultimo trentennio. Mem. Ist. ital. Idrobiol., 37: 197-208.

Barbanti., L., L. Pompilio \& W. Ambrosetti.1996. Morphometry and thermal stratification in Italian lakes. 2 The "Depth Ratio" as a predictive index of thermal structures. Mem. Ist. ital. Idrobiol., 54: 31-42. 
Bowling, L.C. \& K. Salonen. 1990. Heat uptake and resistance to mixing in small humic forest lakes in Southern Finland. Aust. J. Freshwat. Res., 41: 747-759.

Bowling, L.C. 1990. Heat contents, thermal stabilities and Birgean wind work in dystrophic Tasmania lakes and reservoir. Austr. J. Mar. Freshwat. Res., 41: 429-441.

Di Natale, F \& Durio. P.1993. Indagine idrobiologia sui cinque laghi dell'Anfiteatro Morenico di Ivrea. Parte prima: Lago Nero, Lago di Campagna, Lago San Michele. Provincia di Torino Assessorato all'Ecologia: $50 \mathrm{pp}$.

Ferris, J.M. \& H.R. Burton. 1998. The annual cycle of heat content and mechanical stability of hypersaline Deep Lake, vesfold hills, Antartica. Hydrobiologia, 165: 115128.

Garibaldi, L., V. Mezzanotte, M.C. Brizio, M. Rogora \& R. Mosello. 1997. The trofic evolution of Lake Iseo to its holomixis. J. Limnol., 58(1): 10-19.

Geller, W. 1992. The temperature stratification an related characteristic of Chilean lakes in mid summer. Aquat. Sci., 54(1): 37-57.

Gorham, E. 1964. Morphometric control annual heat budget in temperate lakes. Limnol. Oceanogr., 39: 525-529.

Henry, R. \& F.A.R. Barbosa. 1989. Thermal structure, heat content and stability of two lakes in the National Park of Rio Doce Valley (Minas Gerais, Brasil). Hydrobiologia, 171: 189-199.

Hutchinson, G.E. 1957. A treatise on limnology. Vol.1 John Wiley and Sons, New York: 1015pp.

Kjensmo, J. 1994. Internal energy, the work of the wind and the termal stability in Lake Tyrifjord, southeastern Norway. Hydrobiologia, 286: 53-59.

Received: September 2001

Accepted: May 2002
Kling, G.W. 1988. Comparative trasparency, depth of mixing and stability of stratification in lakes od Cameroon, West Africa. Limnol. Oceanogr., 33: 27-40.

Mennella, C. 1967. Il clima d'Italia. Vol. 1. E.D.A.R.T., Napoli: 718 pp.

Mennella, C. 1970. Il clima d'Italia. Vol. 2 E.D.A.R.T., Napoli: $801 \mathrm{pp}$

Michalsky,J.\& U. Lemmin. 1995. dynamics of vertical mixing in the hypolimnion of a deep lake:Lake Geneva. Limnol. Oceanogr., 40: 809-816.

Pompilio, L., W. Ambrosetti \& L. Barbanti.1996. Morphometry and thermal stratification in Italian lakes.1. Predictive models. Mem. Ist. ital.idrobiol., 54:1-29

Reed, E.B. 1970. Annual heat budget a thermal stability in Small Mountain Lakes, Colorado USA. Schweiz. Z. Hydrol., 32: 397-404.

Schindler, D.W. 1971. Light, temperature and oxygen regimes of selected lakes in the Esperimental Lakes Area, Northwestern Ontario. J. Fish. Res. Bd Canada, 28: 157169.

Stewart, K.M. 1973. Detailed time variations in mean teperature and heat content of some Madison Lakes. Limnol. Oceanogr., 18: 218-226.

Timms, B.V. 1975. Morphometric control of variations in annual heat budgets. Limnol. Oceanogr., 20: 110-112.

Viner, A.B. 1984. Resistance to mixing in New Zealanda lakes. N. Z. J. Mar. Freshwat. Res.,18: 73-82.

Wetzel ,R. G., 1983. Limnology, (2nd edition). Saunders College Publishing, N.Y.: 767 pp. 